\title{
Leitthema
}

Gefässchirurgie 2015 [Suppl 1] ·20:22-27

DOI 10.1007/s00772-014-1411-1

Published online: 30. Januar 2015

(c) The Author(s) 2015. This article is published with open access at link.springer.com
W. Schäberle ${ }^{1} \cdot$ L. Leyerer ${ }^{1} \cdot$ W. Schierling ${ }^{2} \cdot K$. Pfister ${ }^{2}$

${ }^{1}$ Klinik für Viszeral-, Gefäß-, Thorax- und Kinderchirurgie, Klinik am Eichert Göppingen

${ }^{2}$ Gefäß- und endovaskuläre Chirurgie, Universitätsklinikum Regensburg

\section{Ultrasound diagnostics of the abdominal aorta}

\section{English version}

\section{Additional material online}

This article includes an additional video on the visualization of an AAA with cardiac cycle-dependent diameter variations. This supplemental can be found at dx.doi.org/10.1007/s00772-014-1411-1.

\section{Introduction}

Ultrasonography of the aorta is primarily performed to detect or exclude an abdominal aortic aneurysm (AAA). Since more than $90 \%$ of AAA are found in the infrarenal abdominal aorta, the occurrence of aneurysm rupture can generally be reduced by ultrasound screening in otherwise symptom-free patients [9]. Other aortic diseases, ranging from stenosis to acute occlusion (Leriche syndrome), embolism caused by thrombosis in peripheral occlusion, dissection, and aortitis are generally assessed in the context of a targeted diagnostic work-up due to relevant symptoms [20]. Ultrasound diagnosis of the aorta is free of side effects, fast, and cost-effective, as a result of which it has been broadly accepted, particularly for AAA screening. Once the examiner has undergone appropriate training, the method has a steep learning curve. Thus, when a suitable examination protocol is used, ultrasonography permits valid examination results that are highly accurate not just in special centers, but on a broad level. Measurement errors and measured value discrepancies compared with gold- standard CT occur due to failure to use standardized measurement methods [outer-to-outer (OTO) or inner-to-inner (ITI) diameter, measurement during systole or diastole, axial or orthogonal measurement plane); however, such errors and discrepancies occur in both examination modes, as discussed below.

\section{Technical equipment requirements and patient preparation}

Due to its anatomical position anterior to the spine, adequate visualization of the aorta depends on an appropriate penetration depth. To this end, low-frequency curved transducers with a frequency of 2-5 MHz are used. In the case of extremely obese patients, extending the frequency range to $1 \mathrm{MHz}$ is helpful.

The examination takes place with the patient in the supine position, the abdominal wall relaxed, and arms positioned parallel to the body. Other patient preparation measures are usually not required. Hampering artefacts caused by intra-abdominal air can be avoided by displacing the intestinal loops from medial to lateral, or compressing air-filled segments, by applying dosed pressure with the transducer. In addition to compressing intra-abdominal air, dosed pressure with the transducer can also reduce the distance from the skin to the aorta, thus improving visualization by reducing the penetration depth. This form of compression is contraindicated for pain reasons only in pre-operated patients with extensive adhesions.

\section{Examination procedure and particular aspects of the ultrasound diagnosis of aortic aneurysms}

In screening programs, the aorta is visualized in transverse cross-section from the diaphragmatic hiatus to the aortic bifurcation, and its maximum diameter (orthogonal) and configuration described. More detailed complementary examinations assess the common, external, and internal iliac arteries in longitudinal and lateral sections for extent and morphology of stenosing and dilatative vascular lesions. An aortic aneurysm is present when the aortic diameter exceeds $3 \mathrm{~cm}$, or in the case of a sudden doubling in aortic cross section at the point of largest diameter compared with aortic diameter in a proximally adjacent section.

Determining the longitudinal extent of an aneurysm is not relevant to treatment and is more likely to cause confusion in the numbers game. However, it is important to localize the aneurysm, including information on whether it begins in a supra- or infrarenal section, as well as on its infrarenal distance from the renal arteries and its extension in a peripheral direction, i.e., involvement of the common iliac artery and possibly the internal iliac ar-

The German version of this article is published in Gefässchirurgie (2014) 19:558-563. 


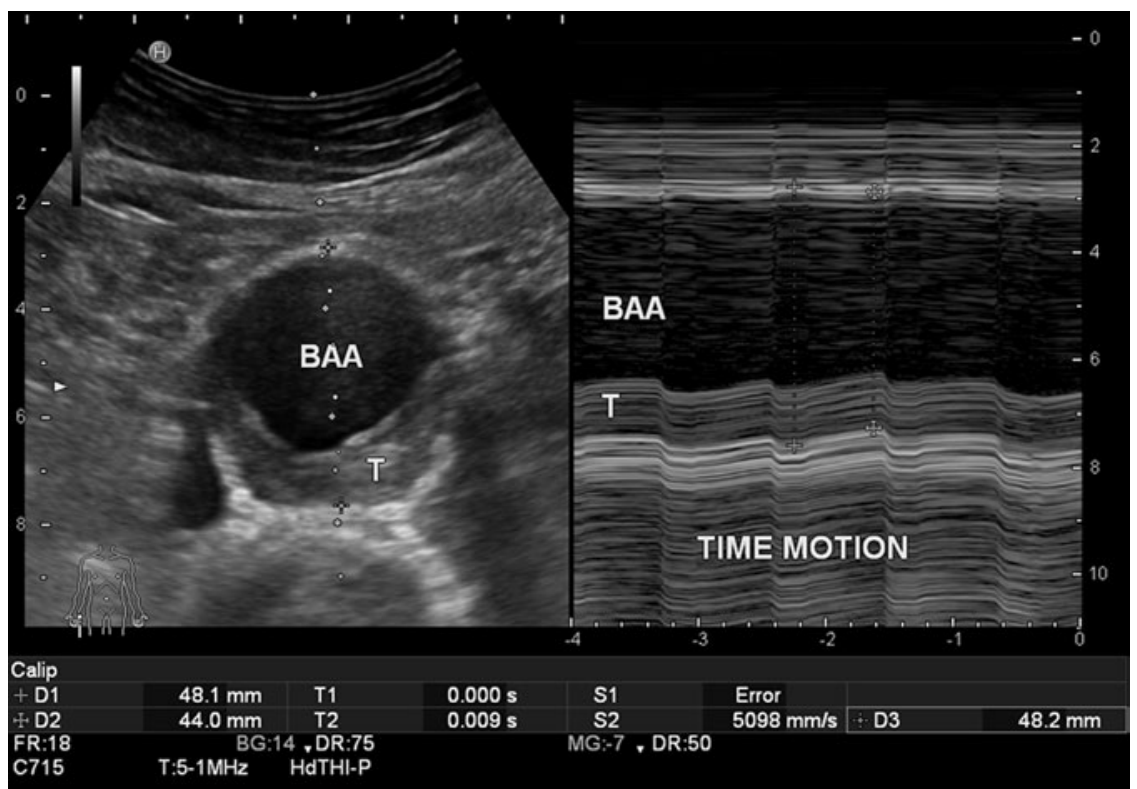

Fig. $1 \Delta$ Diameter fluctuations from $48 \mathrm{~mm}$ (systolic) to $44 \mathrm{~mm}$ (diastolic) in time-motion modus (recording diameter change over time at the point of the sound beam visualized in B-mode). In B-mode cross section (right) with $48 \mathrm{~mm}$ diameter, incidental visualization in systole. Measurements made according to the leading-edge method (see video clip). BAA abdominal aortic aneurysm, $T$ thrombus

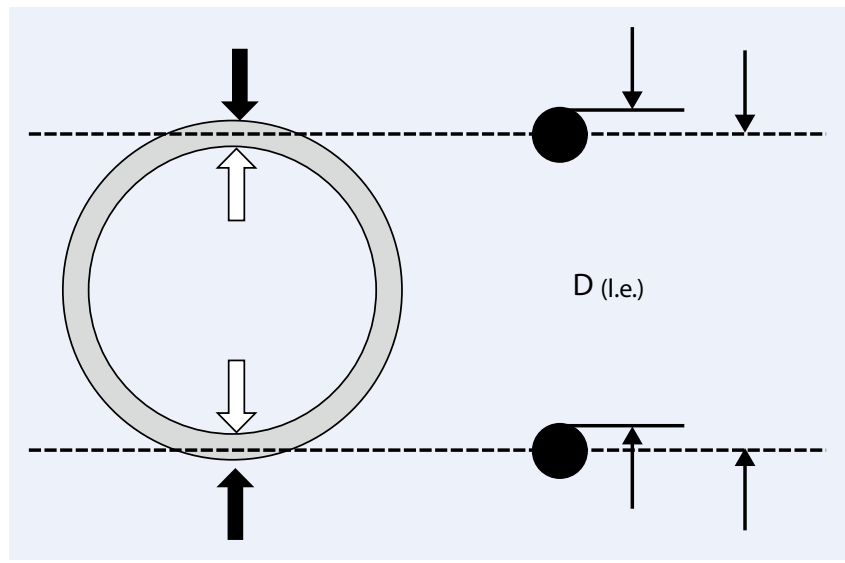

Fig. $2 \Delta$ Measurement according to the outer-to-outer edge (black arrow), the inner-to-inner edge (white arrow), and the leading-edge method (right): outer wall reflection-inner wall reflection $[D($ (l.e.)] of the opposing aortic wall in order to minimize and standardize the ultrasound overestimation of vessel thickness (black dots) caused by the blooming effect at boundaries with high acoustic impedance mismatches (such as vascular wall/blood). (Modified from [20])

tery. In addition to establishing the indication of the surgical method (endovascular approach, standard or special stent graft), a description of aneurysm morphology (thrombus) and the external iliac artery (access route) is relevant. lationship to the renal artery branches, as well as any iliac vein involvement, needs to be assessed. Color duplex ultrasound is only required to distinguish the perfused lumen from wall thrombus and in the differential diagnosis of rare findings, such as inflammatory aortic aneurysm and aortitis (giant cell arteritis). This method also makes is easier to establish the topographical relationship of an aneurysm to the renal arteries, as well as its relationship to the internal iliac artery branch in the case of significant longitudinal extension of the aneurysm.

\section{Particular aspects of measurement methods}

\section{Measuring point and cardiac-cycle dependence}

Precise sonographic determination of the maximum diameter of an aortic aneurysm is decisive not only in establishing the primary indication to monitor or operate a patient, but is also relevant in the comparison of methods, i.e., with computed tomography (CT), in interobserver variance in sonography, and in maximum diameter follow-up. Measurement methods are not standardized either in sonography or in CT. Measurement inaccuracies arising due to varying measurement methods are often ignored [1, 4, 14].

When determining aortic diameter accurately, it must be borne in mind that fluctuations of 2-4 $\mathrm{mm}$ in systolic/diastolic diameter are possible both with a normal aorta as well as in the presence of an aortic aneurysm (• Fig. 1). There are only scant ultrasound studies that address the issue of cardiac cycle-dependent measurements [7], and in statistical CT measurements it is simply not possible to take these fluctuations into consideration for method-specific reasons [4]. This explains small variations both in monitoring as well as in method comparisons. Although ECG-gated measurement would be helpful $[2,3]$, this cannot be required of practice-based screening programs, nor is it practicable.

In addition, no specifications on diameter measurement are made in relation to aortic wall reflection [leading-edge (LELE) method] [4]. Thus, study results 
on OTO diameter determination $[5,8$, 19] generally stand uncommented vis-àvis those determining ITI diameter [11]. Although there appears to be good interand intraobserver variability with these measuring methods [4], ITI measurements inevitably underestimate diameter by $4 \mathrm{~mm}$ on average compared with OTO measurements [4].

It is known from serial measurements of other vessels and ultrasound phantoms that the LELE method (- Fig. 1 and - Fig. 2) yields the most accurate results, since the blooming effect causes an overemphasis of ultrasound reflections at boundaries with high acoustic impedance mismatches, as with vessel walls [20]. Measurements are then made from the outer wall reflection to the opposing inner wall reflection, i.e., from the outer start of the hyperechoic wall reflection to the point of reflection adjacent to the lumen on the opposing side (• Fig. 2).

These particular aspects of the LELE method cause relevant yet not serious measurement inaccuracies (an overall maximum of 5-6 mm) and are therefore less relevant in primary aortic screening. They are however relevant when making the indication for surgery in borderlinesized AAA and monitoring (surgery is indicated if aneurysm diameter increases by $5 \mathrm{~mm}$ within 6 months). Also, when comparing ultrasound with CT, measurement errors can add up and result in statistically significant differences. In general, CT studies of AAA do not address the problems of precise AAA diameter determination described here.

\section{Transducer position and multiplanar reconstruction}

The measurement error produced by transverse cross-sectional upper abdominal determination in the case of an aortic axis visualized obliquely is more serious. Vessel dilatation often causes elongation. The aorta altered by an aneurysm tends to elongate with increasing size, generally following a curved course in a left-lateral direction, possibly also in a ventral direction. Where this is the case, maximum AAA diameter should not be determined ultrasonographically in transverse cross-section of the upper abdomen. This

Gefässchirurgie 2015 [Suppl 1] · 20:22-27 DOI 10.1007/s00772-014-1411-1

(c) The Author(s) 2015. This article is published with open access at link.springer.com

\section{W. Schäberle $\cdot$ L. Leyerer $\cdot$ W. Schierling $\cdot$ K. Pfister Ultrasound diagnostics of the abdominal aorta. English version}

\section{Abstract}

Background and objectives. The ideal method for screening investigations is one which is as free as possible from side effects, is easily learnt, and can therefore be broadly used to detect abdominal aortic aneurysms (AAA) with a high degree of certainty. Although ultrasonography fulfils these criteria, the measurement method is not standardized. Different measurement methods are used in ultrasonography as well as in computed tomography (CT) studies and the measurement method is actually described sufficiently in only $57 \%$ of cases.

Methods. This article provides a critical review of the current literature on measurement methods and the validity of ultrasonography for the determination of aortic diameter, particularly in AAA, and presents the measurement principles for making measurements as precisely as possible.
Results and conclusion. The most precise determination of aortic diameter is carried out by electrocardiogram (ECG) gating according to the leading-edge method with orthogonal slicing. Within the framework of screening investigations, sufficient measurement precision can be achieved by adherence to orthogonal slicing. Using these standardized measurement methods, ultrasonography shows valid and reproducible results even compared with $\mathrm{CT}$ and is the method of choice in screening investigations for AAA.

\section{Keywords}

Sonography · Aortic aneurysm . Measurement methods · Orthogonal measurement $\cdot$ Comparative study CT

\section{Ultraschalldiagnostik der abdominellen Aorta}

\section{Zusammenfassung}

Hintergrund und Fragestellung. Ideal für Screeninguntersuchungen ist eine Methode, die möglichst nebenwirkungsfrei, leicht erlernbar und somit breit einsetzbar mit hoher Treffsicherheit ein abdominelles Aortenaneurysma (AAA) erkennt. Obwohl die Sonographie diese Kriterien erfüllt, ist die Messmethode nicht standardisiert. Sowohl in Ultraschall- als auch in CT-Studien werden unterschiedliche Messmethoden angewandt und nur in $57 \%$ der Fälle wird überhaupt die Messmethode ausreichend beschrieben.

Methode. Kritisches Review der aktuellen Literatur zu Messmethodik und Validität der Sonographie bei der Durchmesserbestimmung der Aorta insbesondere beim AAA und Darstellung von Messprinzipien zur möglichst exakten Messung.

\section{Ergebnisse und Schlussfolgerungen. Die exakteste Durchmesserbestimmung wird EKG-getriggert, nach der Leading-edge- Methode mit orthogonaler Schnittführung (zur Gefäßachse) durchgeführt. Im Rahmen von Screeninguntersuchungen ist eine aus- reichende Messgenauigkeit bei Einhaltung der orthogonalen Schnittführung erreicht. Die Sonographie zeigt bei dieser standardis- ierten Messmethode auch im Methodenver- gleich zum CT valide, reproduzierbare Ergeb- nisse und ist für Screeninguntersuchungen zum AAA die Methode der Wahl.}

\section{Schlüsselwörter}

Sonographie - Aortenaneurysma . Messmethode - Orthogonale Messung . Vergleichsuntersuchung $\mathrm{CT}$ causes, as with axial CT measurement, an elliptical representation resulting in false-high measurements differing by up to $1-1.5 \mathrm{~cm}$ compared with the actual aneurysm measured using multiplanar reconstruction (- Fig. 3a, b, c). Therefore, the transducer must be turned in the area of greatest diameter in such a way that it is perpendicular to the aortic axis and/ or that the ellipsis resumes a round structure in this area (- Fig. 3a, b). In the case of elongation of the aorta in a ventral di- rection, the diameter is best measured in the sagittal plane (- Fig. $3 \mathrm{c}$ ).

Only by standardizing measurement method and transducer position in this way is it possible to monitor patients in an appropriate and reproducible manner. These factors need to be borne in mind in the case of differences in measurement values and when comparing methods (maximum cross-sectional diameter on CT). 

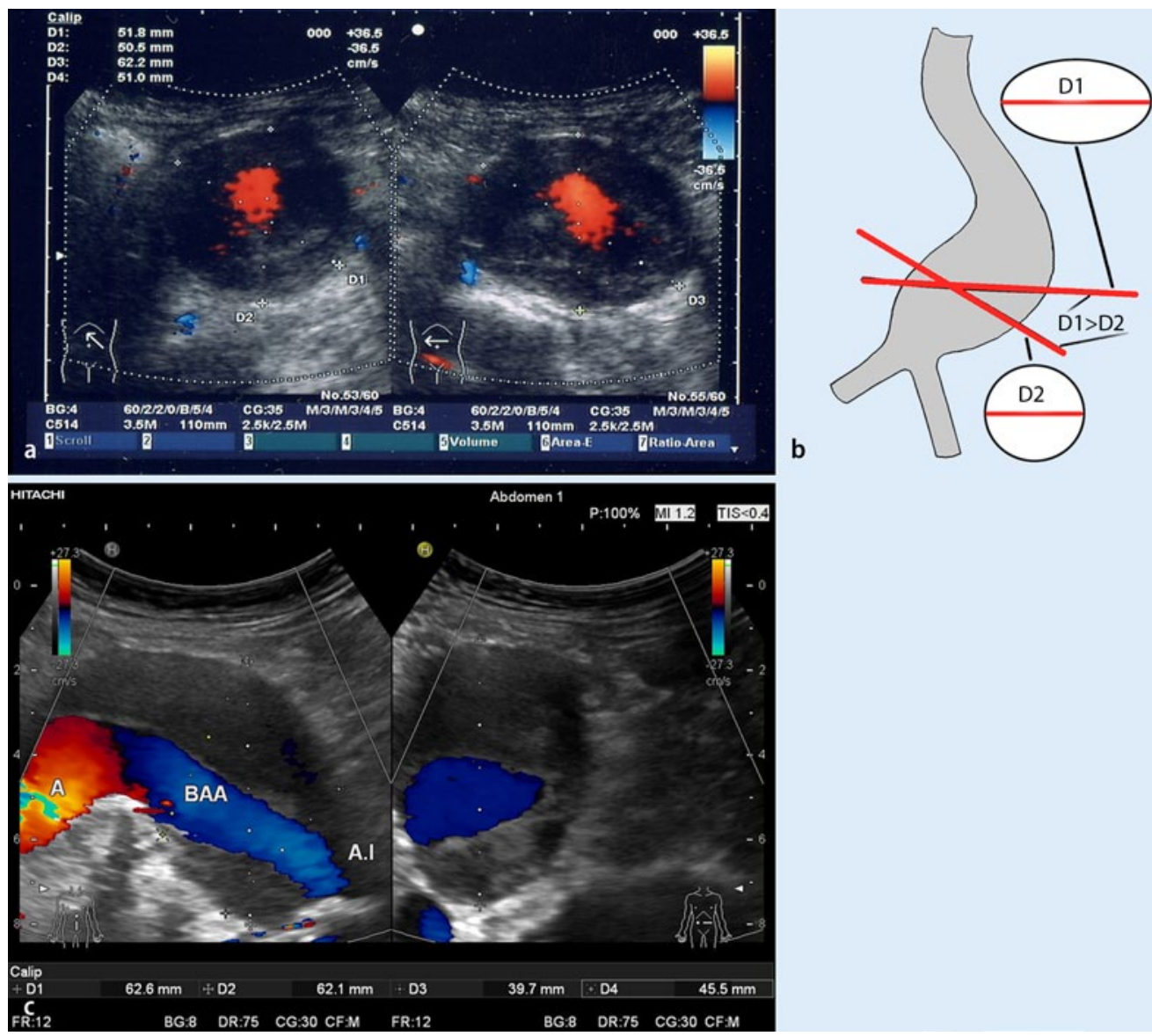

Fig. $3 \Delta$ a Aortic diameter in AAA with left-lateral elongation: comparison of the measurement obtained in upper abdominal cross section (right; see body marker) of $62.2 \mathrm{~mm}(D 3)$ with the measurement of $51.8 \mathrm{~mm}(D 1)$ when the diameter is turned on the vessel axis at the same point (left). The orthogonal diameter measurement (left) corresponds to the real diameter. The anteroposterior (AP) measurement remains constant ( 50.5 and $51 \mathrm{~mm}$ in $D 2$ and D4, respectively). b Appropriate diameter measurement in AAA with an elongated vessel course. Measuring in abdominal cross section results in a false-high diameter due to the elliptical representation obtained in oblique section of the aneurysmal sack (D1). This measurement often also has low reproducibility, resulting in fluctuations in measured values. In order to obtain appropriate as well as reproducible measurements, the transducer should be turned in the area of maximum diameter in such a way that the real aneurysm transverse diameter (D2) perpendicular to the vessel axis is visualized (often a round structure) (modified from [20]). CA comparison of maximum AAA diameter measurement (ventrolateral elongation) of $62.6 \mathrm{~mm}(D 1)$ in abdominal cross section in the AP plane (right) with measurement in the orthogonal plane (perpendicular to the vessel axis in longitudinal section; left). The real aortic diameter here is only a maximum of $45.5 \mathrm{~mm}(D 4)$; at the measurement point in the AP transverse plane, it is only $39.7 \mathrm{~mm}(D 3)$. The measurement of $62.1 \mathrm{~mm}$ in cross section (right) is also marked with measuring marks (D2) in the longitudinal section (left). Diameter measurement in the AP plane in the right-hand section of the image corresponds to the AP measurement on $\mathrm{CT}$ in an axial plane (without reconstruction). BAA abdominal aortic aneurysm, $A . I$ iliac artery

3D ultrasound measurements or image fusion of ultrasound and CT are new and promising approaches to increasing measurement accuracy, particularly in monitoring studies $[2,3,18]$.

\section{Method comparison: ultrasound vs. computed tomography}

According to studies, a comparison of ultrasound and CT methods shows partially discrepant findings [21], often as a result of study design [1]. It should be noted that measurement method and trans- ducer position are rarely specified in ultrasound studies. Of 23 studies [14], only $40 \%$ provided information on the plane in which measurements were made. Only $30 \%$ described the positioning of measurement marks, and only $10 \%$ measured according to the LELE method. Despite a maximum point score of 4 for information on measurement method, an evaluation of studies yielded an average quality score of 2.5. An evaluation of the guidelines on aortic diameter measurement available in screening programs yielded an average score of only 1.6. On the oth- er hand, CT AAA studies provide similarly imprecise information on measurement method, achieving an average quality score of only 1.6. Here again, measurement axis and position (outer or inner diameter) are often not defined $[13,14]$ and the correct measurement point rarely discussed [17]. Where measurement method is specified, it becomes apparent from a comparison of studies that distinct measurement principles have been used [14].

Upon comparison of CT and ultrasound, it is striking that the majority of studies $[10,14,15,22]$ suggest that ultra- 
sound underestimates maximum aneurysm diameter compared with CT (often measured in the AP plane). A closer analysis of studies, however, reveals that the same often applies to transverse diameter on native axial CT without reconstruction. Two studies by Sprouse et al. [22, 23] document this measurement problem impressively. The first study shows that, in $95 \%$ of cases, higher values were measured on axial CT compared with ultrasound measurements. At $5.69 \pm 0.89 \mathrm{~cm}$, the values on CT were significantly higher $(p<0.05)$ than on ultrasound at $4.74 \pm 0.91 \mathrm{~cm}$. In a follow-up study, however, Spouse then describes good concordance between ultrasound and CT measurements when the latter are based on reconstructions from orthogonal slicing. This method showed a mean difference of only $0.8 \mathrm{~mm}$ compared with ultrasound. In contrast, an internal CT comparison of AAA diameter determination showed significantly higher values in axial measurements at $58 \mathrm{~mm}$ on average $(p<0.05)$ compared with orthogonal measurements at $54.7 \mathrm{~mm}$. The greater the aortic angulation, the higher the overestimation was in the axial measurement. This clearly demonstrates that these method-related measurement problems receive too little attention, not only in ultrasound examinations (- Fig. 3b) but also in CT measurements made in routine examinations as well as in the context of studies [14].

CT is generally considered the gold standard due to its lower examiner dependence and lower susceptibility to errors resulting from poor examination conditions. However, a consideration of the measurement problems discussed above renders the discussion on the gold standard in terms of technical equipment in aneurysm diagnosis secondary. It is more important at present to define a gold standard in terms of measurement method, a method according to which measurements and monitoring could be performed in a standardized manner and with which the most precise measurement of true aortic or aneurysmal diameter can be made [LELE method, standardized measurement in systole (or diastole), and orthogonal measurement].

\section{Conclusion}

- B-mode ultrasound is the method of choice as a screening examination in the primary diagnosis of abdominal aortic aneurysm (AAA).

- It is essential for the method of aortic diameter measurement, as well as the measurement plane, to be standardized in order to enable comparative studies and valid monitoring examinations (ECG-gated, LELE method, and orthogonal slicing). In principle, however, this also applies to CT, which is considered the gold standard.

- Orthogonal reconstruction on $\mathrm{CT}$, as well as 3D ultrasound and image fusion represent further approaches to improving comparability of $\mathrm{CT}$ and ultrasound.

\section{Detailed description of the accompanying video}

Visualization of an AAA with cardiac-cycledependent diameter variation in real-time B-mode (left), while diameter variation (systolic/diastolic) is documented in time-motion mode over time (in the anteroposterior plane) (right).

\section{Corresponding address}

\section{Dr. W. Schäberle}

Klinik für Viszeral-, Gefäß-, Thorax- und Kinderchirurgie, Klinik am Eichert Göppingen Eichertstr. 3, 73035 Göppingen

Germany

wilhelm.schaeberle@kae.de

\section{Compliance with ethical guidelines}

Conflict of interest. W. Schäberle, L. Leyerer, W. Schierling and K. Pfister state that there are no conflicts of interest.

The accompanying manuscript does not include studies on humans or animals.

\section{Open Access.}

This article is distributed under the terms of the Creative Commons Attribution License which permits any use, distribution, and reproduction in any medium, provided the original author(s) and the source are credited.

\section{References}

1. Beales L, Wolstenhumlme S, Evans JA et al (2011) Reproducibility of ultrasound measurement of abdominal aorta. Br J Surg 98(11):1517-1525

2. Bredahl K, Taudorf M, Long A et al (2013) Three-dimensional ultrasound improves the accuracy of diameter measurement of the residual sac in EVAR patients. Eur J Vasc Endovasc Surg 46(5):525-532

3. Bredahl K, Eldrup NB, Meyer C et al (2013) Reproducibility of ECG-gated ultrasound diameter assessment of small abdominal aortic aneurysms. Eur J Vasc Endovasc Surg 45(3):235-240

4. Chiu KW, Ling L, Tripathi V et al (2014) Ultrasound measurement for abdominal aortic aneurysm screening: a direct comparison of the three leading methods. Eur J Vasc Endovasc Surg 47(4):367373

5. Ellis M, Powell JT, Greenhalgh RM (1991) Limitations of ultrasonography in surveillance of small abdominal aortic aneurysms. Br J Surg 78(5):614616

6. Foo FJ, Hammond CJ, Goldstone AR et al (2011) Agreement between computed tomography and ultrasound on abdominal aortic aneurysms and implications on clinical decisions. Eur J Vasc Endovasc Surg 42:608-614

7. Grondal N, Bramsen MB, Thomson MD et al (2012) The cardiac cycle is a major contributor to variability in size measurement of infrarenal abdominal aortic aneurysm by ultrasound. Eur JVasc Endovasc Surg 43(1):30-33

8. Harthorne TC, McCollum CN, Earnshaw JJ et al (2011) Ultrasound measurement of aortic diameter in a national screening programme. Eur J Vasc Endovasc Surg 42(2):195-199

9. Hyhlik-Dürr A, Debus S, Eckstein HH et al (2011) Ultrasound screening in abdominal aortic aneurysm - numbers, data, facts. Zentralbl Chir 136(4):390

10. Jaakkola P, Hippeläinen M, Farin P et al (1996) Interobserver variability in measuring the dimension of the abdominal aorta: comparison of ultrasound and computed tomography. Eur J Vasc Endovasc Surg 12:230-237

11. Lanne T, Sandgren T, Mangell P et al (1997) Improved reliability of ultrasonic surveillance of abdominal aortic aneurysms. Eur J Vasc Endovasc Surg 13(2):149-153

12. Lindholdt JS, Vammen S, Juul S et al (1999) The validity of ultrasonographic scanning as screening method for abdominal aortic aneurysm. Eur JVasc Endovasc Surg 17(6):472-475

13. Lederle FA, Wilson SE, Johnson GR et al (1995) For the Abdominal Aortic Aneurysm Detection and Management Veterans Administration Cooperativ Study Group. Variability in measurement of abdominal aortic aneurysms. J Vasc Surg 21:945-952

14. Long A, Rouet L, Lindholdt JS, Allaire E (2012) Measuring the maximum diameter of native abdominal aortic aneurysms: review and critical analysis. Eur J Vasc Endovasc Surg 43:515-521

15. Manning BJ, Kristmundsson T, Sonesson B, Resch $T$ (2009) Abdominal aortic aneurysm diameter: a comparison of ultrasound measurements with those from standard and three-dimensional computed tomography reconstracions. J Vasc Surg 50:263-268

16. Mastracci TM, Ciná CS (2007) Screening for abdominal aortic aneurysm in Canada: review and position statement of the Canadian Society for Vascular Surgery. J Vasc Surg 45(6):1268-1276 
17. Moll FL, Powell JT, Fraedrich G et al (2011) Management of abdominal aortic aneurysms. Clinical practice guidelines of the European Society of vascular Surgery. Eur J Vasc Endovasc Surg 41:51-58

18. Pfister K, Kasprzak P, Apfelbeck H et al (2014) Hochauflösende 3-D-Sonographie und Bildfusion mit der CT-Angiographie - Herausforderungen und Möglichkeiten. Gefässchirurgie (im Druck)

19. Pleumeekers HJ, Hoes AW, Mulder PG et al (1998) Differences in observer variability of ultrasound measurement of the proximal and distal aorta. J Med Screen 5(2):104-108

20. Schäberle W (2011) Ultrasonography in vascular diagnosis, 2nd ed. Springer, Heidelberg, p 18, 400403,441

21. Singh K, Jacobsen BK, Solberg S et al (2004) The difference between ultrasound and computed tomography (CT) measurements of aortic diameter increases with aortic diameter: analysis of axial images of abdominal aortic and common iliac artery diameter in normal and aneurismal aortas. The Tromsø Study, 1994-1995. Eur J Vasc Endovasc Surg 28:158-167

22. Sprouse LR, Meier GH, Lesar CJ et al (2003) A comparison of abdominal aortic aneurysm diameter measurements obtained by ultrasound and computerized tomography: is there a difference? JVasc Surg 38(3):466-471

23. Sprouse LR, Meier GH, Parent FN et al (2004) Is ultrasound more accurate than axial computed tomography for determination of maximal abdominal aortic aneurysm diameter? Eur JVasc Endovasc Surg 28:28-35

24. Thanos J, Rebeira M, Shragge BW, Urbach D (2008) Vascular ultrasound screening for asymptomatic abdominal aortic aneurysm. Health Policy 4(2):7583

25. Thomas PR, Shaw JC, Asthon HA et al (1994) Accuracy of ultrasound in a screening programme for abdominal aortic aneurysms. J Med Screen 1(1):36

26. Vidakovic R, Feringa HH, Kuiper RJ et al (2007) Comparison with computed tomography of two ultrasound devices for diagnosis of abdominal aortic aneurysm. Am J Cardiol 100(12):1786-1791

27. Wanhainen A, Berqvist D, Björck M (2002) Measuring the abdominal aorta with ultrasonography and computed tomography - difference and variability. Eur J Vasc Endovasc Surg 24:428-434 